\title{
Treatment Decision-Making in Metastatic Prostate Cancer: Perceptions of Locus of Control Among Patient, Caregiver, and Physician Triads
}

\author{
Frank A Schumacher (D) \\ Irene B Helenowski ${ }^{1}$ \\ Laura B Oswald (iD ${ }^{2}$ \\ Brian D Gonzalez (D) ${ }^{2}$ \\ James T Benning ' \\ Alicia K Morgans' \\ 'Feinberg School of Medicine, \\ Northwestern University, Chicago, IL, \\ USA; ${ }^{2}$ Program of Health Outcomes and \\ Behavior, Moffitt Cancer Center, Tampa, \\ FL, USA
}

Correspondence: Frank A Schumacher Feinberg School of Medicine, Northwestern University, 1835 W Thomas St, Apt 2F,

Chicago, IL, 60622, USA

$\mathrm{Tel}+\mid$ 3| 4 640-2883

Email frank.schumacher@northwestern.edu
Background: Multiple treatments for metastatic prostate cancer have similar efficacy, leaving patients with complicated treatment choices. Shared decision-making can facilitate difficult treatment decisions, but the extent to which this is used for metastatic prostate cancer is unknown. We assessed patient, caregiver, and physician perceptions of decision locus of control (shared decision-making vs physician- or patient-directed decisions) and the degree of agreement between groups.

Methods: Triads of patients, caregivers, and physicians completed surveys of decisionmaking practices after a clinic visit in which a decision occurred. To evaluate the degree of agreement for decision locus of control, we used the quadratic-weighted kappa coefficient $(\kappa)$. We used relative frequencies to evaluate which knowledge learned and treatment factors were most strongly endorsed by patients as informing and influencing their treatment decision-making, respectively.

Results: Fifty triads participated, with median patient age of 72 years. A majority of patients, caregivers, and physicians reported shared decision-making $(66 \%, 56 \%$, and 52\%, respectively). Patients and physicians demonstrated minimal agreement about decision locus of control $(44 \%, \kappa=0.35$ [SD $=0.52])$, but caregiver reports were not statistically significantly associated with physician and patient reports $(38 \%, \kappa=0.23,[\mathrm{SD}=0.28]), p=0.055$; $44 \%, \kappa=0.34$ [SD $=1.98$ ],$p=0.14)$. Treatment efficacy was the most common patientreported factor influencing treatment decisions (44\%).

Conclusion: This study characterized metastatic prostate cancer patients', caregivers', and physicians' experiences and communication preferences for treatment decision-making. Patients and physicians had greater agreement in decision locus of control compared with caregivers, yet patient-physician agreement was minimal. Metastatic prostate cancer patients report being influenced by information about treatment efficacy and clear next steps, and a desire for patient-friendly language and an invitation to be as involved in decision making at their preferred level. Emphasizing these may increase agreement in decision locus of control between all participants in the decision-making process.

Keywords: prostate cancer, decision making, shared decision making, treatment decisions, cancer survivorship

\section{Background}

Prostate cancer is the most common non-cutaneous malignancy and the second most common cause of cancer-related death among American men, affecting 1 in 8 American men in their lifetime. ${ }^{1}$ Although localized prostate cancer is highly 
treatable, metastatic prostate cancer remains incurable. However, recent treatment advances have transformed metastatic prostate cancer into a disease that patients routinely live with for years. There are multiple systemic treatment options available for men with metastatic prostate cancer, all with differing side effect profiles, financial obligations, and delivery modalities. Often, there is not a single recommended treatment option based on expected efficacy, and the optimal treatment paradigm remains an active area of investigation. Given the lack of evidencebased guidelines suggesting optimal treatment sequencing, treatment choices are often driven by physician preferences and experience, rather than medical necessity or scientific evidence. ${ }^{2}$ Ideally, treatment decisions should be patient-centered, or driven by patient preferences for factors patients consider important, such as treatment side effects, administration schedule, financial toxicity or others identified by the patients. ${ }^{3}$ This process may be facilitated by shared decision-making, which has been identified by the Institute of Medicine, the American Urological Association, and others as a priority method to improve the quality of cancer care in the US through patient engagement and autonomy. ${ }^{4-6}$ In shared decisionmaking, patients and providers work collaboratively to make treatment decisions based on a combination of clinical information and the patient's individual values and preferences.

Decision-making preferences are highly individualized and may vary widely among cancer patients, with patients reporting heterogeneous preferences for decision-making roles. $^{7-10}$ The extent to which patients with metastatic prostate cancer participate in shared decision-making has not been described, yet this is critical for understanding their treatment decision-role practices and preferences. This information, in turn, may enable physicians to meet patients' needs more effectively, potentially improving decision satisfaction, aligning expectations for treatment outcomes, and addressing other aspects of patient quality of life. ${ }^{11}$ Therefore, the primary goal of this study was to characterize the decision making roles and preferences of men with metastatic prostate cancer as perceived by the patients, their caregivers, and their physicians. This study also assessed the information patients learned during the process of making treatment decisions, and what topics influenced treatment decisions from the patient's perspective. Finally, this study evaluated what physicians can do to help patients make important treatment decisions.

\section{Methods}

\section{Participants and Procedures}

We assessed metastatic prostate cancer treatment decisionmaking roles among patients, caregivers, and providers within 48 hours of making a treatment decision in a clinical setting in a cross-sectional quantitative study. This study was approved by the Institutional Review Board at Vanderbilt University Medical Center (VUMC; approval \#160649). Between 12/ 2016 and 11/2017, men with metastatic prostate cancer and their caregivers were recruited from Vanderbilt University Medical Center's Genitourinary Medical Oncology and Urology clinics. Eligible patients had a history of metastatic prostate cancer (and may have received prior systemic/local therapies), were accompanied by a caregiver at a clinic visit, spoke English, were able to recall a decision at a clinic visit within the preceding 48 hours, and signed informed consent to participate. Patients completed surveys online. Provider surveys were completed on paper within 24 hours of the qualifying clinic visit at which patients were recruited. We also recruited patients via a collaboration with ZERO, a nonprofit organization supporting patients with prostate cancer, to collect post-clinic visit surveys online. This allowed a broader geographic distribution of participants. Patient sociodemographic and clinical characteristics, including age, race/ethnicity, marital/partner status, self-reported health status (excellent, good, fair, or poor), and insurance status, were collected by patient report.

\section{Surveys}

Patient Surveys

Within 48 hours of a clinic visit in which a treatment decision was made, participants completed online surveys describing the role they played in the decision (decision locus of control) using a modified version of the Control Preferences Scale, ${ }^{9,12,13}$ which has been used in assessments of decision making among patients with cancer and is reliable in defining

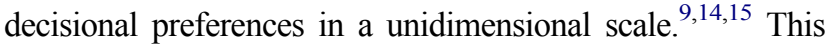
modified version of this 5-item scale classifies decision roles as physician-controlled ("Your doctors made the decision with little or no input from you." or "Your doctors made the decisions after seriously considering your opinion."), shared decision-making ("You and your doctors made the decisions together."), or patient-controlled ("You made the decisions after seriously considering your doctor's opinion." or "You made the decision with little or no input from your doctors."). Participants rated their agreement with statements about treatment decision-making preferences on a Likert-type scale from 
"strongly agree" (1) to "strongly disagree" (5) (Appendix 1). Patients also completed an investigator-developed survey assessing whether they learned new information during the decision-making process, and what aspect of the discussion with their physician most influenced their treatment decision (Appendix 2). This survey was created using information gathered from a mixed-methods study of treatment decisionmaking in men with prostate cancer. ${ }^{2}$ Lastly, patients completed the Communication Assessment Tool, a 15-item survey that is reliable and valid in identifying patient perceptions of physicians' interpersonal and communication skills. ${ }^{16}$ The analysis was modified by asking participants to identify the five most important things that physicians can do to help them make treatment decisions, and answer options were ranked in order of most commonly identified.

\section{Caregiver Surveys}

Within 48 hours of a clinic visit in which a treatment decision was made, caregivers that had accompanied participants to the clinic visit completed an adapted version of the Control Preferences Scale that reflected their perspective of the decision locus of control during the decisionmaking process (Appendix 3).

\section{Physician Surveys}

Within 48 hours of a clinic visit in which a treatment decision was made, physicians completed an adapted version of the Control Preferences Scale that reflected their perspective of the decision locus of control during the decision-making process (Appendix 4).

\section{Data Analysis}

We used descriptive statistics to summarize patients' sociodemographic characteristics, clinical factors, and participants' perceptions of decision locus of control. We used Fisher's exact tests to evaluate the relationships between patients' perceptions of decision locus of control and their sociodemographic characteristics including age, overall health status, and physician specialty. To evaluate the degree of agreement between patient, caregiver, and physician perceptions of decision locus of control, we used the quadraticweighted kappa coefficient ( $\kappa)$. Agreement was evaluated on an overall basis and by patient age group (5-year increments) with values $0-0.2$ indicating no agreement, $0.21-0.39$ indicating minimal agreement, $0.40-0.59$ indicating weak agreement, $0.60-0.79$ indicating moderate agreement, $0.80-0.90$ indicating strong agreement, and $0.90-1.0$ indicating nearly perfect agreement. ${ }^{17}$ Significance was determined by $p<0.05$.
We used relative frequencies to determine the information patients most strongly endorsed learning during the clinic visit (ie, proportion of participants who responded "definitely" to a given topic vs other response). Item responses were dichotomized in this way to allow us to identify the type of information learned that was endorsed most strongly by patients. We used the same approach to describe which topics discussed with their physician most strongly influenced patients' treatment decision (ie, proportion of participants who responded "definitely" for each topic vs other response). We then used Fisher's exact tests to explore associations between participant characteristics and likelihood of strongly endorsing each item across the following participant characteristics: age (median split $<72$ vs $\geq 72$ years old), race (nonWhite vs White), marital status (married/partnered vs not married/partnered), and self-reported health (poor/fair vs good/excellent). Significance was determined by $p<0.05$. Finally, we used relative frequencies to rank the five most commonly identified things that physicians could do to help patients make treatment decisions.

\section{Results}

\section{Participant Characteristics}

Data from 50 patients were collected and are summarized in Table 1. Most patients were White (96\%), married $(90 \%)$, reported good health or better (18\% excellent, $58 \%$ good, $24 \%$ fair, $0 \%$ poor), and the median age was 72 years.

\section{Patient-Caregiver-Physician Triad Perceptions of Decision Locus of Control}

Shared decision-making was the most common locus of control across patients, caregivers, and physicians (Table 2, Figure 1). No patients, caregivers, or physicians reported that a decision was made with "little to no input" from the treating physician. For patients, the next most common loci of control were physician-directed considering the patient's opinion (12\%) and patient-directed considering the physician's opinion $(12 \%)$. All patient-directed decisions that were reported occurred in medical oncology visits rather than urology visits. For caregivers, the next most common locus of control was patient-directed considering the physician's opinion $(30 \%)$. For physicians, the second most common locus of control was physician-directed (18\%). Of the 11 patients who reported a physician-directed decision, all stated that they had asked the doctor to make the decision for them because of the physician's medical knowledge or because the patient 
Table I Descriptive Statistics of Patient Demographic Characteristics

\begin{tabular}{|c|c|}
\hline Demographic Variable & Value \\
\hline \multicolumn{2}{|l|}{ Age } \\
\hline Mean (SD) & $70.9(8.43)$ \\
\hline Median (range) & $72.0(53.0-89.0)$ \\
\hline \multicolumn{2}{|l|}{ Race } \\
\hline White/Caucasian (not Latino/Hispanic) (n, \%) & $48(96 \%)$ \\
\hline Black/African American (not Latino/Hispanic) (n, \%) & $2(4 \%)$ \\
\hline \multicolumn{2}{|l|}{ Marital Status } \\
\hline Married (n, \%) & $45(90 \%)$ \\
\hline Widowed (n, \%) & $4(8 \%)$ \\
\hline Divorced (n, \%) & I (2\%) \\
\hline \multicolumn{2}{|l|}{ Living Situation } \\
\hline Alone $(\mathrm{n}, \%)$ & $2(4 \%)$ \\
\hline With spouse/partner (n, \%) & $46(92 \%)$ \\
\hline With others (n, \%) & $2(4 \%)$ \\
\hline \multicolumn{2}{|l|}{ Insurance Status } \\
\hline Not insured $(n, \%)$ & I (2\%) \\
\hline Insured (n, \%) & 49 (98\%) \\
\hline \multicolumn{2}{|l|}{ Overall Health Status } \\
\hline Excellent (n, \%) & $9(18 \%)$ \\
\hline Good $(n, \%)$ & $29(58 \%)$ \\
\hline Fair $(\mathrm{n}, \%)$ & $12(24 \%)$ \\
\hline Poor (n, \%) & $0(0 \%)$ \\
\hline \multicolumn{2}{|l|}{ Specialty of Treating Physician } \\
\hline Medical Oncologist (n, \%) & $29(58 \%)$ \\
\hline Urologist (n, \%) & $21(42 \%)$ \\
\hline
\end{tabular}

believed the doctor knew what was best for them. None of these patients reported that their physician did not offer them treatment options. In contrast, of the 17 physicians who reported a physician-directed decision, 8 (47\%) reported directing the decision because they "knew which treatment was superior in this particular medical situation and did not offer options to the patient." The other 9 physicians (53\%) reported that the patient asked them to make the decision for various reasons. Patients' reported decision locus of control was evaluated according to various patient and physician
Table 2 Stakeholder Reports of Decision Locus of Control

\begin{tabular}{|l|l|l|l|}
\hline $\begin{array}{l}\text { Decision Locus of } \\
\text { Control }\end{array}$ & Patient & Caregiver & Physician \\
\hline Physician-directed alone & $5(10 \%)$ & $3(6 \%)$ & $9(18 \%)$ \\
\hline $\begin{array}{l}\text { Physician-directed } \\
\text { considering patient }\end{array}$ & $6(12 \%)$ & $4(8 \%)$ & $8(16 \%)$ \\
\hline Shared decision & $33(66 \%)$ & $28(56 \%)$ & $26(52 \%)$ \\
\hline $\begin{array}{l}\text { Patient-directed considering } \\
\text { physician }\end{array}$ & $6(12 \%)$ & $15(30 \%)$ & $7(14 \%)$ \\
\hline Patient-directed alone & $0(0 \%)$ & $0(0 \%)$ & $0(0 \%)$ \\
\hline
\end{tabular}

demographics. There was no association between decision locus of control and patient age or overall patient health status ( $p=0.73, p=0.61$, respectively). There was also no association between decision locus of control and physician specialty $(p=0.08)$.

\section{Assessment of Decision Locus of Control Agreement Among Stakeholders}

Patients and physicians demonstrated weak agreement about decision locus of control overall (weighted $\kappa=0.35$; $\mathrm{SD}=0.52 ; p=0.01)$. Patients and physicians demonstrated agreement regarding decision locus of control in $44 \%$ of cases, with shared decision-making being the most common agreed-upon perceived decision locus of control (36\% of agreed upon cases). Relative to physicians, $34 \%$ of patients reported more patient influence on decision locus of control, and $22 \%$ of patients reported less patient influence on decision locus of control.

In contrast, caregiver reports of decision locus of control were not statistically significantly associated with physician reports (weighted $\kappa=0.23 ; \mathrm{SD}=0.28$; $p=0.055$ ). Overall, caregivers and physicians agreed on decision locus of control in $38 \%$ of cases, and shared decision-making was the most common agreed-upon decision locus of control (32\%). Relative to physicians, $46 \%$ of caregivers reported more patient influence on decision locus of control and $16 \%$ of caregivers reported less patient influence. Caregiver reports were not statistically significantly associated with patient reports (weighted $\kappa=0.34 ; \mathrm{SD}=1.98 ; p=0.14)$. Caregivers and patients agreed in $44 \%$ of cases. Relative to patients, $40 \%$ of caregivers reported more patient influence and $16 \%$ reported less patient influence on decision locus of control. 


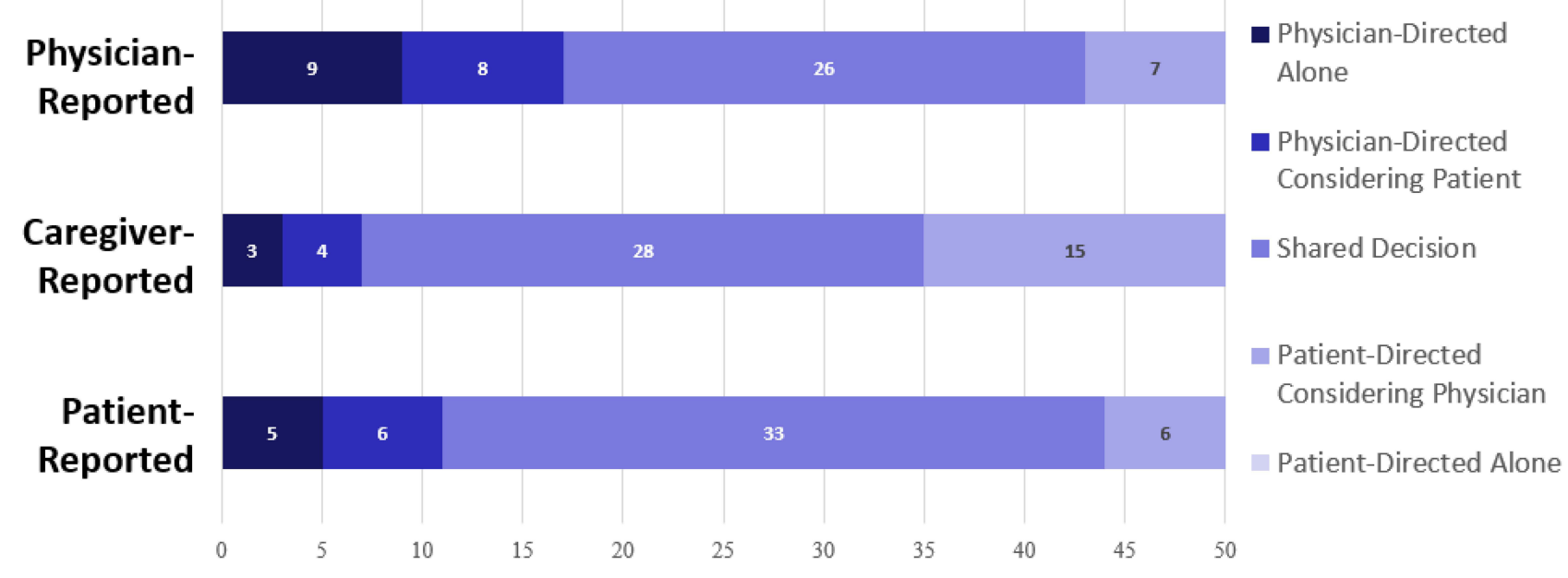

Figure I Stakeholder reports of decision locus of control.

\section{Influence of Information Learned on Patients' Treatment Decision}

Patients reported on the information that they learned during their clinic visit with physicians (Table 3, Figure 2). The most common aspects of care that patients strongly endorsed learning new information about were frequency of follow-up care (36\%), how well the treatment works (32\% of patients), and side effects of treatment (32\%). New information about out-of-pocket costs was infrequently learned by patients (12\%).

Patients also reported on which information influenced their treatment decision (Table 4, Figure 2). Treatment efficacy was the most common influencer of treatment decisions ( $44 \%$ of patients), with side effects, follow-up care, and cost less commonly endorsed $(22 \%, 10 \%, 6 \%$, respectively).

\section{Physician-Controlled Factors Important to Patients and Caregivers}

Patients identified the most important things their physicians did to help them with treatment decision making (Table 5, Figure 3). For patients, the three most highly rated factors were discussing next steps for care, including follow-up plans ( $62 \%$ endorsed as one of the top five most important); speaking in terms the patient could understand (56\%); and involving patients in decisions as much as they wanted $(52 \%)$. The three most highly rated factors by caregivers similarly included speaking in terms the caregiver could understand (68\%) and discussing next steps (64\%). Unlike patients, caregivers rated understanding the patient's health concerns $(60 \%)$ as the third most highly rated factor rather than involvement in decisions (26\%).

\section{Discussion}

This study characterized the experiences of patients, caregivers, and physicians in making treatment decisions for metastatic prostate cancer, including defining their perceived decision locus of control during a clinic visit in which all three shareholders were present. Most patients, caregivers, and physicians reported that decisions were shared, and smaller proportions of patients, caregivers, and physicians reported primarily physician- or patientdirected decisions. These findings suggest that the three groups were actively engaging in the decision-making

Table 3 Information Learned by Patients During Visit

\begin{tabular}{|l|l|l|l|l|}
\hline Information Learned & \multicolumn{1}{|c|}{ Definitely } & \multicolumn{1}{|c|}{ Somewhat } & \multicolumn{1}{|c|}{ Neutral } & Not Very Much/Not at All \\
\hline How well the treatment works & $16(32 \%)$ & $8(16 \%)$ & $\mathrm{I}(2 \%)$ & $25(50 \%)$ \\
\hline Side effects of treatment & $16(32 \%)$ & $3(6 \%)$ & $0(0 \%)$ & $31(62 \%)$ \\
\hline Out-of-pocket costs & $6(12 \%)$ & $\mathrm{I}(2 \%)$ & $0(0 \%)$ & $43(86 \%)$ \\
\hline Frequency of follow-up & $18(36 \%)$ & $4(8 \%)$ & $\mathrm{I}(2 \%)$ & $27(54 \%)$ \\
\hline
\end{tabular}




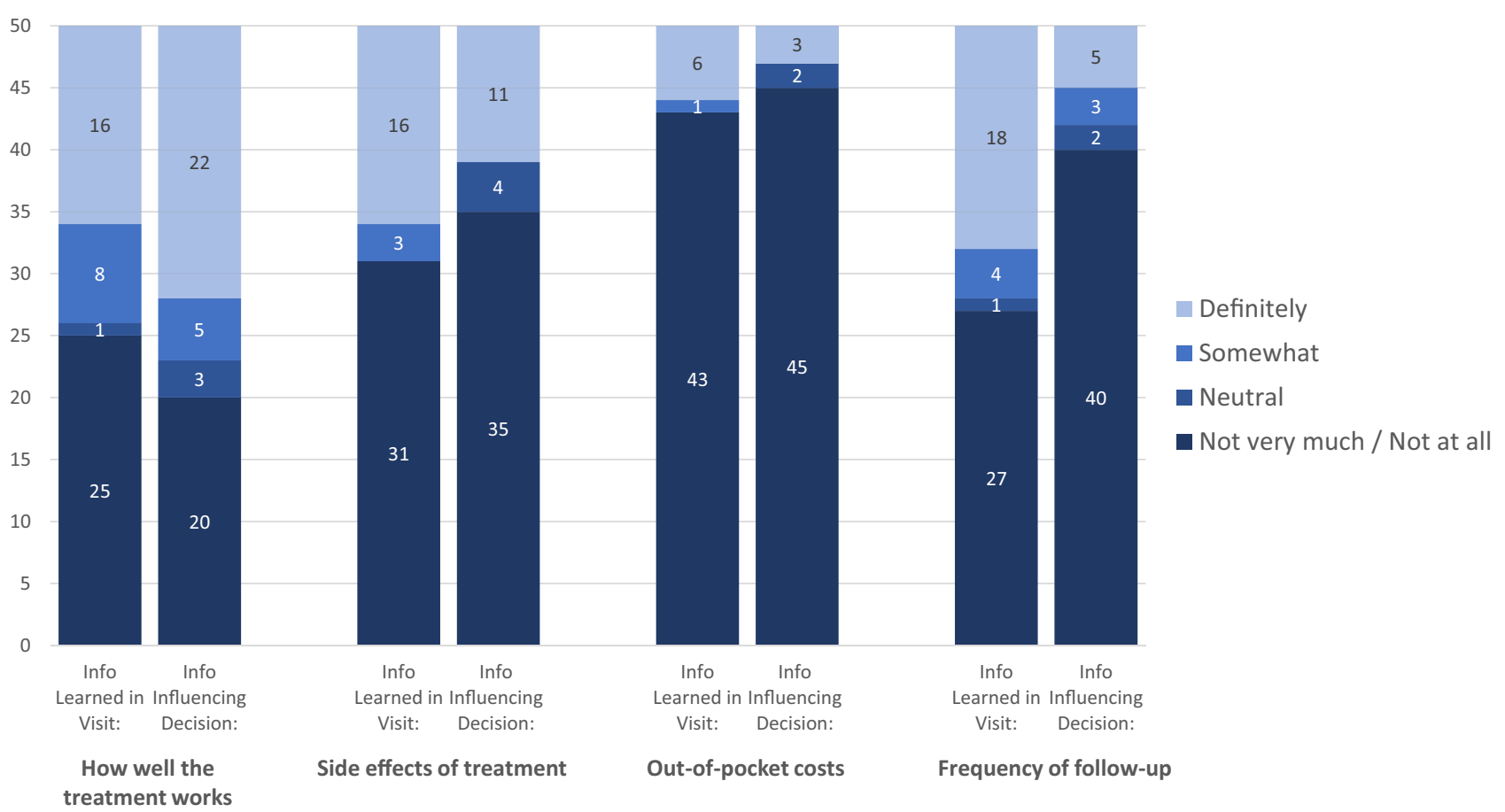

Figure 2 Patient reports of information learned in visits / influencing treatment decision.

process according to their perception and as reported by the other parties involved. All patient-directed decisions that were reported occurred at a medical oncology visit rather than urology visit. Finally, although half of physicians that reported a physician-directed decision explained that they did not offer some treatment options because they felt that they knew what was best for the patient, patients reporting physician-directed decisions did not feel that treatment options were withheld. Shared decision-making is strongly valued and included in medical education and thus is a laudable goal. However, we do not yet understand the preferences for decision locus of control among this patient population, and patient satisfaction may not suffer if patients are not preferring shared decisions.

Overall there was a relatively low level of agreement between patients and physicians, but there was a higher degree of agreement with their treating physician regarding decision locus of control than the level reported between caregivers and physicians. Previous studies similarly found that there is more frequent disagreement between physicians and caregivers, as compared with physicians and patients. ${ }^{18}$ There are a number of factors that may result in this discrepancy between caregivers and physicians versus patients and physicians, including the traditional focus of treatment decision-making discussions on the patient due to an emphasis in healthcare on the importance of patient autonomy. As a concept, patient autonomy is strongly valued, is included in all medical school curricula, and is a key tenet of biomedical ethics. ${ }^{19}$ However, the disconnect between physicians and caregivers raises the possibility that there is an opportunity to engage with caregivers more effectively, particularly for patients with advanced cancer whose treatment decisions

Table 4 Information Influencing Patients' Treatment Decision

\begin{tabular}{|l|l|l|l|l|}
\hline Information Influencing Decision & \multicolumn{1}{|c|}{ Definitely } & \multicolumn{1}{|c|}{ Somewhat } & \multicolumn{1}{|c|}{ Neutral } & Not Very Much/Not at All \\
\hline How well the treatment works & $22(44 \%)$ & $5(10 \%)$ & $3(6 \%)$ & $20(40 \%)$ \\
\hline Side effects of treatment & $11(22 \%)$ & $0(0 \%)$ & $4(8 \%)$ & $35(70 \%)$ \\
\hline Out-of-pocket costs & $3(6 \%)$ & $0(0 \%)$ & $2(4 \%)$ & $45(90 \%)$ \\
\hline Frequency of follow-up & $5(10 \%)$ & $3(6 \%)$ & $2(4 \%)$ & $40(80 \%)$ \\
\hline
\end{tabular}


Table 5 Physician Factors Endorsed by Patients and Caregivers to Aid in Decision-Making

\begin{tabular}{|c|c|c|}
\hline Factors Aiding Decision-Making & $\begin{array}{c}\text { Patients Reporting as Top } 5 \text { Most } \\
\text { Important }\end{array}$ & $\begin{array}{c}\text { Caregivers Reporting as Top } 5 \text { Most } \\
\text { Important }\end{array}$ \\
\hline Discussed next steps, including follow-up plans & $31(62 \%)$ & $32(64 \%)$ \\
\hline Talked in terms I could understand & $28(56 \%)$ & $34(68 \%)$ \\
\hline Involved me in decisions as much as I wanted & $26(52 \%)$ & $13(26 \%)$ \\
\hline Understood my health concerns & $24(48 \%)$ & $30(60 \%)$ \\
\hline Gave me as much information as I wanted & $22(44 \%)$ & $20(40 \%)$ \\
\hline $\begin{array}{l}\text { Paid attention to me (looked at me, listened } \\
\text { carefully) }\end{array}$ & $20(40 \%)$ & $6(12 \%)$ \\
\hline Treated me with respect & $19(38 \%)$ & $12(24 \%)$ \\
\hline Greeted me in a way that made me comfortable & $15(30 \%)$ & $18(36 \%)$ \\
\hline Checked to be sure I understood everything & $15(30 \%)$ & $18(36 \%)$ \\
\hline Encouraged me to ask questions & $13(26 \%)$ & $14(28 \%)$ \\
\hline Showed care and concern & $12(24 \%)$ & $20(40 \%)$ \\
\hline Spent the right amount of time with me & II (22\%) & $12(24 \%)$ \\
\hline Showed interest in my ideas about my health & $7(14 \%)$ & $13(26 \%)$ \\
\hline Let me talk without interruptions & 7 (I4\%) & $8(16 \%)$ \\
\hline
\end{tabular}

may profoundly affect caregivers as well. In a recently reported study of treatment decision making in oncology, $74.4 \%$ of caregivers reported that they participated significantly in treatment decisions with patients, but that they needed additional support to communicate with the healthcare team and patient in the process. ${ }^{19}$ Importantly,

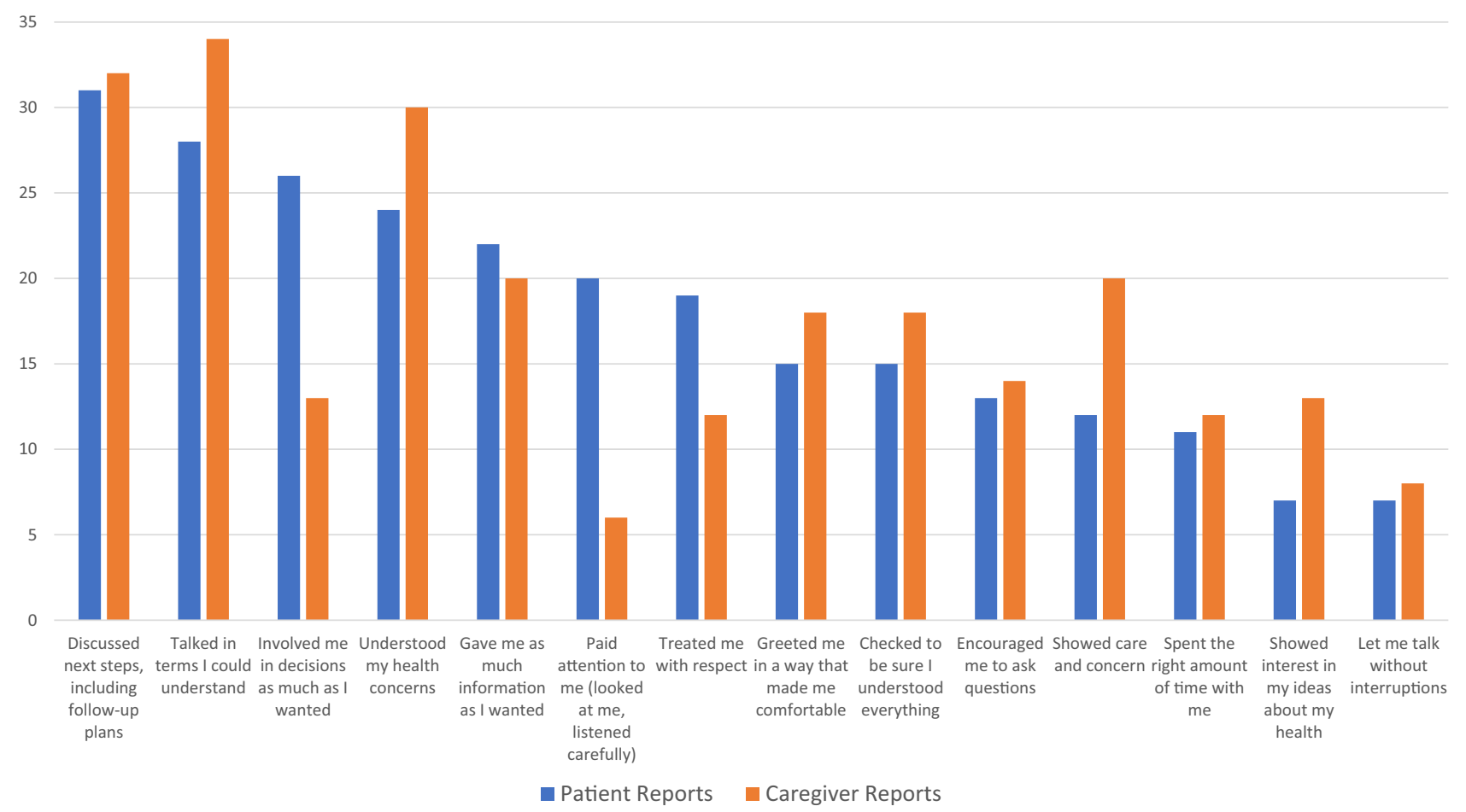

Figure 3 Physician factors endorsed by patients and caregivers to aid in decision-making. 
caregivers may have different goals for treatment and different expectations of outcome from patients, which must be addressed to fully engage them in the decision-making process. Despite literature suggesting that caregivers are involved, it is not known whether caregiver-physician agreement has an impact on disease control or quality of life outcomes that are important to patients when making treatment choices, or whether they contribute to aligning patient expectations of outcome with those of the healthcare team. ${ }^{2,21}$ Given the significant role caregivers play in providing physical and psychosocial support to patients throughout cancer treatment, caregiver-physician alignment may play a role in improving patient outcomes, and deserves future investigation. Further work defining how caregiver involvement affects these outcomes may inform physician practices and future decision aids to promote their involvement in treatment decisions and in supporting patients after decisions are made.

Understanding the factors that metastatic prostate cancer patients value the most in making decisions about their care is critical to facilitating opportunities for shared decisions and ensuring that patients, caregivers, and physicians are in agreement over the visit. Nearly half of the patients in the study reported that information about treatment efficacy "definitely" influenced their treatment decision. However, only about one third reported learning something new about treatment efficacy during the visit in which they made a treatment decision. This discrepancy suggests that there is an opportunity for physicians to include more information defining expected treatment efficacy in these discussions, or to provide efficacy information in ways that are more meaningful to patients. Consciously considering health literacy and numeracy in treatment conversations may enable physicians to do this more effectively. Other factors that are routinely incorporated by clinical teams into treatment decisions to ensure patient safety and access to treatment, including discussions of side effects, cost, and follow-up frequency, were less influential in patients' decision-making in this cohort. Specifically, a large majority of patients reported these factors were of minimal importance when making decisions about cancer treatment. This may be due to patients anchoring on efficacy as the single most important quality of a therapy, and a willingness to sacrifice aspects of other domains to receive the treatment with highest efficacy. It is unclear whether these patient views may be influenced by the physicians' focus during these conversations on treatment efficacy, as is suggested by what patients report learning the most about.
Patients with a poor/fair health status were more likely to be influenced in their decision-making by side effect information than men with good/excellent health status, suggesting that patients may value a focus that maximizes their quality of life when they are in poorer health. Separate literature supports this finding and suggests that physicians are more likely to emphasize quality of life over survival benefit for patients in poor health. ${ }^{20}$ Thus, patients' goals in this setting may be more likely to be inline with physicians' treatment goals and focus during treatment discussion.

When asked to pick the five most important things that physicians could do to aid in treatment decision-making, patients identified the top three factors as discussing next steps including follow-up plans, speaking in patientfriendly terms, and involving patients as much as they desired. Given this, physicians facing these treatment discussions may consider incorporating teach-back strategies that have demonstrated efficacy in communication in educational settings in which patients can reflect back their understanding of next steps prior to concluding a visit. ${ }^{22}$ This may increase the likelihood that all next steps and follow-up plans are clear to the patient. This strategy may also display to the physician whether or not they have been speaking in patient-friendly language, as this is a primary reason why patients may not have a full understanding of the treatment plan. A separate strategy that may improve the patient experience and address the issue of patient engagement is an approach in which physicians use a brief time at the beginning of the visit to align with patients and caregivers on how much they wish to be involved in the treatment decision-making process. Patient preferences for treatment decision-making roles are highly individualized, and thus aligning with patients on an individual basis may be helpful in meeting their needs. Of note, prior work in oncology populations suggests that even among patients who prefer greater or lesser involvement in decision-making, shared decisions are associated with higher patient-reported quality of care, suggesting that engaging patients in the final steps of the decision process remains important. ${ }^{11}$

Recall bias is a potential limitation of this and any study relying upon patient report. To address this, we limited enrollment to participants who could recall treatment decisions within 48 hours. We also recognize that enrolling patients from the VUMC clinics alone limits the heterogeneity of our population, which included mostly White, married, and insured patients. Thus, results may 
not be reflecting decision making practices in more diverse populations of patients with metastatic prostate cancer. Future studies assessing decision making in men with prostate cancer in a more racially diverse population are critical to ensure clinician understanding of the broader array of decision making preferences and factors that influence the decision making process in this population.

Understanding the perceptions of patients about decision locus of control in treatment decision-making for men with metastatic prostate cancer is an important first step toward creating a patient-centered approach to treatment that incorporates patient preferences. Patients in this study reported that treatment efficacy is the most important factor that influenced their treatment decision-making, followed by side effects of treatment. Additionally, the most important physician communication factors that aided patients in decision-making were discussing next steps including follow-up plans, speaking in patient-friendly terms, and involving patients as much as they desired. Physicians that are aware of the factors within their control that patients most value will be better equipped to address patient concerns with limited time, and may develop stronger patient-physician relationships that can improve the patient experience and may positively affect treatment adherence and disease related outcomes.

In conclusion, this paper summarizes decision-making roles of patients with metastatic prostate cancer, as observed by the patients themselves, their caregivers, and their providers in treatment decisions faced in routine clinical encounters. We have identified that a majority of men, their caregivers, and their physicians report that treatment decisions are shared, suggesting that engagement with patients and their loved ones is a priority of clinical teams during treatment discussions. Further work that broadens our understanding of decision making practices in diverse populations that more adequately reflect the ethnic and sociodemographic extent of men living with advanced prostate cancer is needed to more fully characterize the decision making process and support optimal treatment conversations.

\section{Ethics Approval}

This study was conducted in accordance with the Declaration of Helsinki.

\section{Acknowledgments}

This paper was presented at the American Society of Clinical Oncology meeting as a poster presentation with interim findings. The poster's abstract was published in "Poster Abstracts" in Journal of Clinical Oncology: https:// ascopubs.org/doi/abs/10.1200/JCO.2020.38.6 suppl.224.

\section{Disclosure}

Dr Brian Gonzalez reports personal fees from SureMed Compliance and KemPharm, advisory board for Elly Health, outside the submitted work. Mr James Benning reports grants from Department of Defense, during the conduct of the study. Dr Alicia Morgans reports personal fees from Astellas, AstraZeneca, Advanced Accelerator Applications, Bayer, Clovis, Dendreon, Myovant, Exelixis, Blue Earth, Lantheus, Novartis, Pfizer, Janssen, and Sanofi, outside the submitted work. The authors report no other conflicts of interest in this work.

\section{References}

1. American Cancer Society. Cancer Facts and Figures; 2021.

2. NCCN guidelines; 2021.

3. Oswald LB, Schumacher FA, Gonzalez BD, Moses KA, Penson DF, Morgans AK. What do men with metastatic prostate cancer consider when making treatment decisions? A Mixed-methods Study. Patient Prefer Adherence. 2020;14(14):1949-1959. doi:10.2147/PPA.S271620

4. National comprehensive cancer network clinical practice guidelines in oncology. Prostate Cancer, Version 4; 2013. Available from: http:// www.nccn.org/professionals/physician_gls/pdf/prostate.pdf. Accessed March 20, 2015.

5. Institute of Medicine (US) Committee on Quality of Health Care in America. Crossing the Quality Chasm: A New Health System for the 21st Century. Washington (DC): National Academies Press (US); 2001. Accessed January 12, 2022.

6. Levit L, Balogh E, Nass S, Ganz PA. Institute of Medicine. Delivering High-Quality Cancer Care: Charting a New Course for a System in Crisis. Washington, DC: National Academies Press; 2013. PMID: 24872984. Available from: http://www.nap.edu/open book.php?record_id=18359. Accessed December 16, 2021.

7. Agency for Healthcare Research and Quality: 2015Annual Progress Report to Congress: National Strategy for Quality Improvement in Health Care. 2015. Available from: https://www.ahrq.gov/workingfor quality/reports/2015-annual-report.html. Accessed January 12, 2022.

8. Elkin EB, Kim SHM, Casper ES, et al. Desire for information and involvement in treatment decisions: elderly cancer patients' preferences and their physician perceptions. J Clin Oncol. 2007;25:5275-5280. PMID: 18024875. doi:10.1200/JCO.2007.11.1922

9. Degner LF, Sloan JA. Decision making during serious illness: what role do patients really want to play? J Clin Epidemiol. 1992;45 (9):941-950. PMID: 1432023. doi:10.1016/0895-4356(92)90110-9

10. Keating NL, Guadagnoli E, Landrum MB, Borbas C, Weeks JC. Treatment decision making in early-stage breast cancer: should surgeons match patients' desired level of involvement? J Clin Oncol. 2002;20 (6):1473-1479. PMID: 11896094. doi:10.1200/JCO.2002.20.6.1473

11. Oswald LB, Kasimer R, Rappazzo K, Fought AJ, Penson DF, Morgans AK. Patient expectations of benefit from systemic treatments for metastatic prostate cancer. Cancer Med. 2020;9 (3):980-987. doi:10.1002/cam4.2783

12. Hawley ST, Lantz PM, Janz NK, et al. Factors associated with patient involvement in surgical treatment decision making for breast cancer. Patient Educ Couns. 2007;65(3):387-395. PMCID: PMC1839840. doi:10.1016/j.pec.2006.09.010 
13. Kehl KL, Landrum MC, Arora NK, et al. Association of actual and preferred decision roles with patient-reported quality of care: shared decision making in cancer care. JAMA Oncol. 2015;1(1):50-58. PMID: 26182303. doi:10.1001/jamaoncol.2014.112

14. Degner LF, Kristjanson LJ, Bowman D, et al. Information needs and decisional preferences in women with breast cancer. JAMA. 1997;277 (18):1485-1492. PMID: 9145723. doi:10.1001/jama.1997.035 40420081039

15. Beaver K, Luker KA, Owens RG, Leinster SJ, Degner LF. Treatment decision making in women newly diagnosed with breast cancer. Cancer Nurs. 1996;19:8-19. doi:10.1097/00002820-19960200000002

16. Bilodeau BA, Degner LF. Information needs, sources of information, and decisional roles in women with breast cancer. Oncol Nurs Forum. 1996;23:691-696.

17. Makoul G, Krupat E, Chang CH. Measuring patient views of physician communication skills: development and testing of the communication assessment tool. Patient Educ Couns. 2007;67(3):333-342. doi:10.1016/j.pec.2007.05.005
18. McHugh ML. Interrater reliability: the kappa statistic. Biochem Med. 2012;22(3):276-282. doi:10.11613/BM.2012.031

19. LeBlanc TW, Bloom N, Wolf SP, et al. Triadic treatment decision-making in advanced cancer: a pilot study of the roles and perceptions of patients, caregivers, and oncologists. Support Care Cancer. 2018;26(4):1197-1205. doi:10.1007/s00520-017-3942-y

20. Entwistle VA, Carter SM, Cribb A, McCaffery K. Supporting patient autonomy: the importance of clinician-patient relationships. J Gen Intern Med. 2010;25(7):741-745. doi:10.1007/s11606-010-1292-2

21. Zhang AY, Siminoff LA. The role of the family in treatment decision making by patients with cancer. Oncol Nurs Forum. 2003;30 (6):1022-1028. doi:10.1188/03.ONF.1022-1028

22. Ha Dinh TT, Bonner A, Clark R, Ramsbotham J, Hines S. The effectiveness of the teach-back method on adherence and self-management in health education for people with chronic disease: a systematic review. JBI Database Syst Rev Implement Rep. 2016;14 (1):210-247. doi:10.11124/jbisrir-2016-2296
Patient Preference and Adherence

\section{Publish your work in this journal}

Patient Preference and Adherence is an international, peer-reviewed, open access journal that focusing on the growing importance of patient preference and adherence throughout the therapeutic continuum. Patient satisfaction, acceptability, quality of life, compliance, persistence and their role in developing new therapeutic modalities and compounds to optimize clinical outcomes for existing disease states are major areas of interest for the journal. This journal has been accepted for indexing on PubMed Central. The manuscript management system is completely online and includes a very quick and fair peer-review system, which is all easy to use. Visit http:// www.dovepress.com/testimonials.php to read real quotes from published authors. 